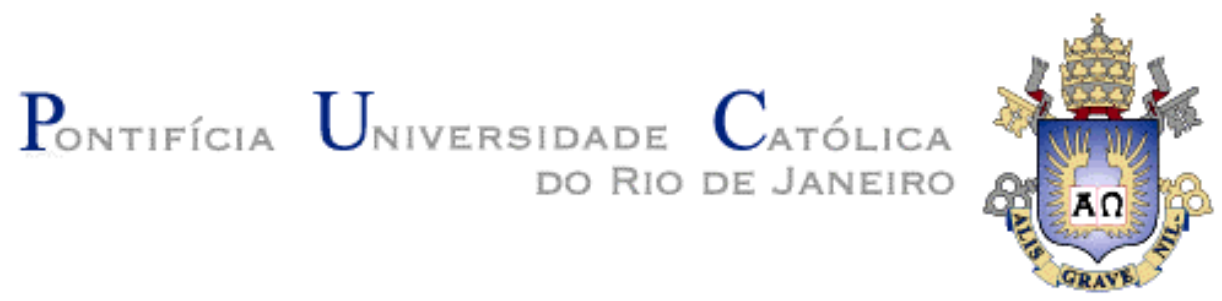

André de Barros Borges

\title{
O ENSINAMENTO NIETZSCHIANO ATRAVÉS DO GÊNIO PARA A FORMAÇAO DE UM NOVO TIPO HUMANO
}

Dissertação de Mestrado

Departamento de Filosofia

Pontifícia Universidade Católica do Rio de Janeiro

Rio de Janeiro, março de 2004 


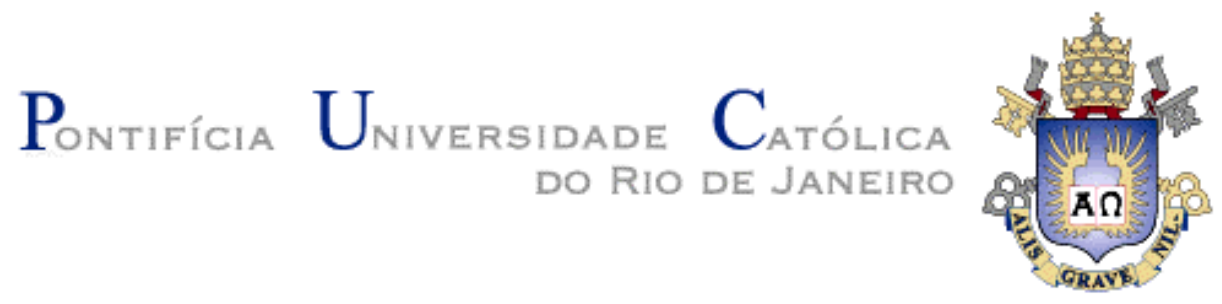

André de Barros Borges

O ENSINAMENTO NIETZSCHIANO ATRAVÉS DO GÊNIO PARA A FORMAÇAO DE UM NOVO TIPO HUMANO

Dissertação apresentada ao Departamento de Filosofia da PUC-RIO como parte dos requisitos para obtenção do título de Mestre em Filosofia

Orientador: Prof ${ }^{\mathrm{a}}$. Dr ${ }^{\mathrm{a}}$. Kátia Muricy

Departamento de Filosofia

Pontifícia Universidade Católica do Rio de Janeiro

Rio de Janeiro, março de 2004 


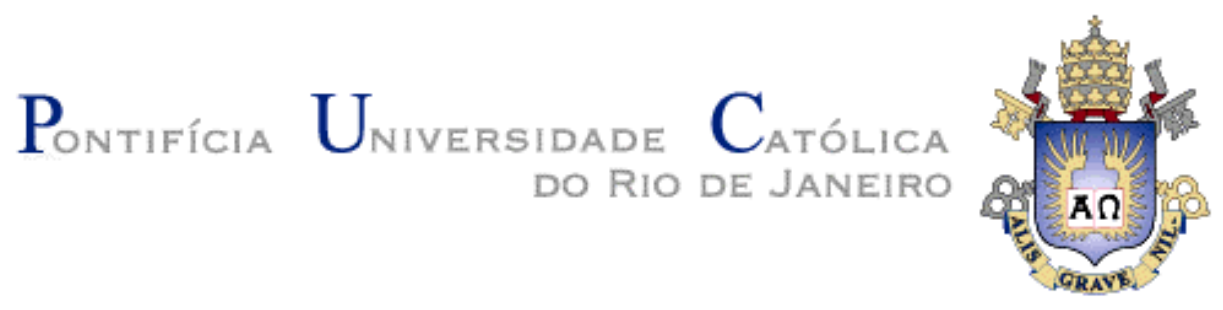

André de Barros Borges

O ensinamento nietzschiano através do gênio para a formação de um novo tipo humano

Dissertação apresentada como requisito parcial apara obtenção do grau de Mestre pelo Programa de Pós-Graduação em Filosofia do Centro de Teologia e Ciências Humanas da PUC-Rio. Aprovada pela Comissão Examinadora abaixo assinada.

Prof ${ }^{a}$. Kátia Rodrigues Muricy

(Orientadora)

Departamento de Filosofia - PUC-Rio

Prof. Paulo Cesar Duque Estrada Departamento de Filosofia - PUC-Rio

Prof. Eduardo Jardim de Moraes Departamento de Filosofia - PUC-Rio

Prof. Paulo Fernando Carneiro de Andrade Coordenador Setorial do Centro de Teologia e Ciências Humanas - PUC-Rio

Rio de Janeiro, 15 de março de 2004. 
Todos os Direitos reservados. È proibida a reprodução total ou parcial do trabalho sem autorização da Universidade, do autor e do orientador.

\section{André de Barros Borges}

Graduou-se em Direito pela Universidade Católica de Goiás no ano de 2000. No mesmo ano também se graduou em Filosofia pela Universidade Federal de Goiás. Em 2002 ingressou no Mestrado em Filosofia pela PUC-Rio, onde concluiu em março de 2004 com a apresentação desta dissertação. Foi professor no Departamento de Direito da Universidade Católica de Petrópolis entre 2003 e 2004. Atualmente é professor da Universidade de Brasília - UNB, ligado ao Departamento de "Teoria e Fundamentos - TEF" onde leciona disciplinas relacionadas a "Filosofia da Educação".

Ficha Catalográfica

Borges, André de Barros

O Ensinamento nietzschiano através do gênio para a formação de um novo tipo humano / André de Barros Borges ; orientadora:

Kátia Muricy. - Rio de Janeiro : PUC-Rio, Departamento de Filosofia, 2004.

98 f. ; $30 \mathrm{~cm}$

Dissertação (mestrado) - Pontifícia Universidade Católica do Rio de Janeiro, Departamento de Filosofia.

Inclui referências bibliográficas

1. Filosofia - Teses. 2. Transvaloração. 3. Criação artística. 4. Gênio. I. Muricy, Kátia. II. Pontifícia Universidade Católica do Rio de Janeiro. Departamento de Filosofia. III. Título. 


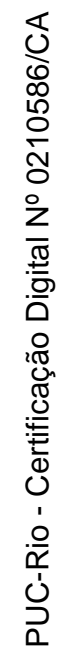

Para Luanda 


\section{AGRADECIMENTOS}

Agradeço a CAPES, Coordenação de Aperfeiçoamento de Pessoal de Nível Superior, pelo apoio financeiro sem o qual não teria sido possível realizar esta pesquisa.

Não posso deixar de agradecer três pessoas muito especiais para a minha formação filosófica: O professor Dr. Roberto Machado, da Universidade Federal do Rio de Janeiro, a quem tive o prazer de conhecer em 1997, quando ainda cursava a graduação em filosofia pela Universidade Federal de Goiás. Pisar no solo romântico alemão não teria sido possível sem as brilhantes aulas proferidas pelo professor Roberto Machado nos anos de 2001, sobre Hörderlin e Schiller, e 2002, sobre Schelling e Hegel, e em 2003 sobre Schopenhauer e Nietzsche. Tive a preciosa oportunidade de assistir a todos estes cursos, que me fizeram admirar e respeitar ainda mais este grande filósofo brasileiro. Não posso também deixar de mencionar o nome do querido amigo José Nicolao Julião, professor doutor da Universidade Federal Rural do Rio de Janeiro e que muito contribuiu para o avanço das minhas pesquisas, sendo um grande incentivador dos meus estudos filosóficos. Agradeço também a professora Kátia Muricy, minha orientadora, que me encorajou para que traçasse o meu próprio caminho, neste emaranhado de conceitos que é a filosofia. Através dela percebi com maior clareza que o educador, antes de tudo, precisa conceder liberdade para o educando trilhar seu caminho da forma mais autêntica possível.

O curso do Professor Eduardo Jardim sobre o "tempo" em Aristóteles, Santo Agostinho e Heidegger me fizeram também compreender Nietzsche para além da dimensão somente estética.

Encontrar ecos de Nietzsche na contemporaneidade foi-me possível, em grande parte, graças aos cursos do Professor Dr. Paulo César Duque Estrada. Seu curso sobre a Justiça em Derrida, através do texto "Força da Lei", foi fundamental para minha formação filosófica e para o surgimento de novas questões que inspiraram novos projetos. No segundo semestre de 2002, seu curso sobre A obra de arte no pensamento de Heidegger e Derrida muito contribuiu para a compreensão de minha própria dissertação, me orientando melhor no campo da filosofia da arte.

Agradeço finalmente ao meu pai, Paulo Cezar Borges, amigo de todas as horas. 


\section{RESUMO}

Borges, André de Barros. O ensinamento nietzschiano através do gênio para a formação de um novo tipo humano. Rio de Janeiro, 2004, 97 p. Dissertação de Mestrado - Departamento de Filosofia, Pontifícia Universidade Católica do Rio de Janeiro.

A dissertação trata da idéia de gênio desenvolvida por Nietzsche e sua relação com a tradição filosófica - principalmente Kant, o Romantismo alemão e Schopenhauer. Mostramos como Nietzsche modifica o conceito cunhado pela tradição e inova sua significação. A idéia de gênio em Nietzsche pode ser compreendida em dois momentos. $\mathrm{O}$ primeiro é o que aparece no livro $O$ Nascimento da Tragédia, onde o gênio possui um caráter sobre-humano capaz de revelar uma verdade fundamental, por meio da arte. No segundo momento arte e vida não mais se diferenciam.

Nietzsche aproximará tal noção de gênio à vida, se afastando da concepção forjada pela dita tradição filosófica, onde o conceito de gênio designa um talento inato, e nada pode ser feito para despertar este talento. Procuramos mostrar que Nietzsche parece falar antes da dificuldade da formação de um indivíduo autêntico do que da impossibilidade total desta tarefa, visto que, a partir da constatação da não essencialidade dos valores, certos homens podem criar e também se tornar gênios.

Nietzsche parece propor um certo ensinamento de como se tornar um indivíduo autêntico, capaz de criar seus próprios valores e afirmar a vida, apesar de toda sua falta de sentido. Assim, o ensinamento é paralelo ao desenvolvimento de suas reflexões sobre o gênio, que tem na capacidade criativa sua principal característica.

Palavras-chave: gênio, criação artística, transvaloração. 


\begin{abstract}
Borges, André de Barros. The Nietzsche's teaching of genius for the formation

of a new type of human. Rio de Janeiro, 2004, 97 p. MSc. Dissertation -

Departamento de Filosofia, Pontifícia Universidade Católica do Rio de Janeiro.
\end{abstract}

This dissertation is about the idea of genius developed by Nietzsche in its relation to Kant, German Romantism and Schopenhauer. These show how Nietzsche modifies the concept shaped by tradition and innovates the current signification. The idea of genius in Nietzsche may be understood in two moments. The first one appears in The Birth of Tragedy, where the genius had an extra-human character that can reveal a fundamental truth by art. In the second moment Nietzsche shows the similiarities between art and life.

Nietzsche approximated the notion of genius with the notion of life. He takes distance of the conception shaped by philosophical tradition, where the concept of genius means an innate talent and nothing can make this talent appear. We tried to show that Nietzsche speaks about the difficulty for the development of an authentic individual, instead of the impossibility of this task. After the evidence that the values don't have any essence in itself, some individuals can create and become genius.

Nietzsche seems to propose a certainly education to be an authentic individual, able to create his own values and enhance life, although its non-sense. Therefore, this education is parallel of the development of his reflections about genius, who have in creative capacity his major characteristic.

Keywords: genius, artistic creation, transvaloration. 


\section{SUMÁRIO}

Introdução 09

Capítulo 1 - Gênio e metafísica 13

1.1. O gênio na Antiguidade: entre gregos e romanos 13

1.2. O gênio em $O$ Nascimento da Tragédia: o Arquíloco 18

1.3. O gênio no romantismo alemão: Schiller e Schelling 26

Capítulo 2 - O gênio de Kant: imaginação, entendimento, espírito e gosto 35

2.1. A criação artística __ 36

2.1.1. Imaginação___ 38

2.1.2. Entendimento __ 39

2.1.3. Espírito _ 40

2.1.4. Gosto _ _ 41

2.2. O gênio além da arte__ 42

Capítulo 3 - Nietzsche e Schopenhauer___ 53

3.1. Princípio de razão e vontade _ـ 53

3.2. A contemplação artística e o homem de gênio___ 59

3.3. O gênio e a loucura ___ 60

Capítulo 4 - Para além de um gênio metafísico__ 69

4.1. Educação e transvaloração ___ 69

4.2. Zaratustra : o ensinamento de Nietzsche __ 77

4.3. Educação para o gênio em Assim Falou Zaratustra: as 4 etapas ___ 81

Conclusão __ 89

Referências Bibliográficas ___ 93 
“Não existe na natureza criatura mais sinistra e mais repugnante do que o homem que foi despojado de seu próprio gênio e que se extravia agora a torto e a direito, em todas as direções.” ( Friedrich Nietzsche, Schopenhauer como Educador) 